\title{
Interleukin 8: cells of origin in inflammatory bowel disease
}

\author{
M C Grimm, S K O Elsbury, P Pavli, W F Doe
}

\begin{abstract}
Neutrophils are important cellular mediators in inflammatory bowel disease (IBD). Interleukin (IL)8, a powerful neutrophil chemoattractant, is found in increased quantities in inflamed mucosa, but the cells of origin are uncertain. IL8 gene expression was studied by in situ hybridisation in uninflamed intestinal tissue resected for colon carcinoma $(n=7)$ and in inflamed colonic tissue resected for IBD (n=11). Immunohistochemistry was used to assess the phenotype of IL8 expressing macrophages and the production of IL8 protein. Macrophages isolated from intestinal resections and lipopolysaccharide stimulated peripheral blood monocytes treated with 5-aminosalicylic acid, hydrocortisone, and cyclosporin A were examined for IL8 mRNA by northern blotting and IL8 secretion by enzyme linked immunosorbent assay (ELISA). In all cases IL8 mRNA was detected by in situ hybridisation in macrophages and neutrophils adjacent to ulceration in inflamed bowel, but not detected in uninflamed mucosa from carcinoma resections. Recently recruited CD14 positive
\end{abstract} macrophages were responsible for some of this IL8 expression. IL8 protein was present in the same distribution as mRNA. Epithelial cells in normal and inflamed tissue showed neither mRNA nor protein. IL8 mRNA was expressed significantly more commonly by macrophages from IBD affected than from normal mucosa, and IL8 secretion by IBD but not normal colon macrophages was augmented significantly by lipopolysaccharide treatment. IL8 expression and production by lipopolysaccharide treated blood monocytes was inhibited by the therapeutic agents tested. These results show that neutrophils and recently recruited macrophages are responsible for production of IL8 in IBD, suggesting a mechanism for a continuing cycle of neutrophil attraction. Agents used therapeutically in these diseases may be effective in part by disrupting this cycle.

(Gut 1996; 38: 90-98)

Keywords: interleukin 8, macrophage, polymorphonuclear leucocyte, inflammatory bowel disease, in situ hybridisation, immunohistochemistry.

Inflammatory bowel diseases (IBD) are characterised by the accumulation of inflammatory cells, including neutrophils, monocytes, lymphocytes, and plasma cells, in the lamina propria of affected intestine. While many of these cells have potential effector functions in mediating continuing tissue injury, neutrophils play a major part in acute mucosal inflammation because of the enormous numbers present in inflamed intestine ${ }^{1}$ and because of their potent ability to produce toxic mediators such as reactive oxygen and nitrogen intermediates ${ }^{2}$ as well as cytokines. ${ }^{3}$

Neutrophil turnover in active IBD has been shown by radioisotope labelled leucocyte scans to be greatly increased. ${ }^{4}$ Some of the signals responsible for the attraction and activation of neutrophils, including leukotriene $\mathrm{B}_{4}$, platelet activating factor, granulocytemacrophage colony stimulating factor (GMCSF), and interleukin (IL) 8 have been shown to be increased in the serum and inflamed mucosa of patients suffering from active IBD. ${ }^{5-9}$ The relative contributions of the different neutrophil chemoattractants however, is not clear.

IL8, a member of the $\alpha$ chemokine family of chemotactic cytokines, is a potent chemoattractant and activator of neutrophils. ${ }^{10} \mathrm{It}$ is produced by a wide variety of cell types, including macrophages, neutrophils, $T$ cells, endothelial cells, keratinocytes, fibroblasts, hepatocytes, and chondrocytes in vitro (reviewed in ref 11), and is found in various disease states, including psoriasis, ${ }^{12}$ rheumatoid arthritis, ${ }^{13}$ occlusive vascular disease, ${ }^{14}$ and septic shock. ${ }^{15}$ In addition, there is good evidence that some transformed intestinal epithelial cell lines can be stimulated to produce IL $8^{1617}$ as can primary cultures of intestinal epithelial cells ${ }^{18}$ but whether mucosal epithelial cells produce IL8 in the IBD intestinal lesion is not clear.

Despite the findings of increased IL8 in IBD and the large number of cell types capable of producing this cytokine, the cells responsible for its expression and secretion in the inflamed intestinal environment are yet to be elucidated. We report here that recently recruited mucosal macrophages and neutrophils but not epithelial cells are prominent producers of IL8 in actively inflamed IBD tissue as shown in situ, suggesting a positive feedback loop of neutrophil attraction in these diseases. Isolated intestinal macrophages also express and secrete IL8, and agents used in the treatment of IBD are capable of inhibiting IL8 production, suggesting that at least part of their efficacy may result from inhibition of neutrophil recruitment.
Dr M C Grimm, Division of Molecular Medicine, John Curtin School of Medical Research, PO Box 334 Australia.

Accepted for publication 13 June 1995 


\section{Methods}

\section{Patients}

Resected intestinal tissue was obtained from 16 patients suffering from Crohn's disease and eight suffering from ulcerative colitis. The mean age of IBD patients was 27 years (range 17-49). All were being treated with corticosteroids at the time of surgery, five of eight ulcerative colitis patients were being treated with sulphasalazine or 5-aminosalicylic acid and two of the Crohn's disease patients were receiving azathioprine. Histologically uninflamed intestinal tissue was obtained more than five centimetres from carcinoma in 19 patients undergoing surgery for colonic cancer. The mean age of these patients was 63 years (range 52-75).

\section{IL8 in situ hybridisation}

Sense and antisense riboprobes for IL8 were produced from an IL8 cDNA (450 bp EcoR1 fragment in pUC 19 vector - generous gift from Dr Mark Smyth, Austin Hospital, Melbourne, Australia) by restriction enzyme digestion and subcloning into the EcoR1 site of the pGEM- $4 Z$ vector (Promega, Madison, WI, USA). The plasmid was linearised using Eae1 or Sma1 and labelled with ${ }^{35}$ S-UTP by transcription using T7 or SP6 RNA polymerases (Promega), to generate antisense and sense riboprobes respectively. These then were cut into approximately $100 \mathrm{bp}$ fragments by alkaline hydrolysis. ${ }^{19}$ In situ hybridisation of intestinal tissue was performed as described previously..$^{20}$ Briefly, formalin fixed, paraffin wax embedded tissue from IBD (six Crohn's disease and five ulcerative colitis) and uninflamed, cancer bearing colons $(n=7)$ was cut into $3 \mu \mathrm{m}$ sections, dewaxed, and treated for 20 minutes in $0.2 \mathrm{M} \mathrm{HCl}$. Sections then were permeabilised using proteinase $\mathrm{K} 50 \mu \mathrm{g} / \mathrm{ml}$ (Sigma, St Louis, MO, USA), fixed in $4 \%$ paraformaldehyde, and acetylated using acetic anhydride $0.2 \%$ in $100 \mathrm{mM}$ triethanolamine, before dehydration in alcohol and overnight hybridisation at $47^{\circ} \mathrm{C}$ with sense or antisense IL8 riboprobes in $50 \%$ formamide, $1 \times$ Denhardt's solution, $0.3 \mathrm{M} \mathrm{NaCl}, 5 \times 10^{-4} \mathrm{M}$ EDTA, $0.01 \mathrm{M}$ TRIS, $5 \times 10^{-3} \mathrm{M} \mathrm{Na}_{2} \mathrm{HPO}_{4}$, $5 \times 10^{-3} \mathrm{M} \mathrm{NaH}_{2} \mathrm{PO}_{4}, 10 \%$ dextran sulphate, transfer RNA $1 \mu \mathrm{g} / \mathrm{ml}$ (Sigma, St Louis, MO) and $10 \mathrm{mM}$ dithiothreitol (DTT; Kodak, New haven, CT, USA). Subsequently sections were washed in hybridisation solution at $50^{\circ} \mathrm{C}$ then NTE $(\mathrm{NaCl} 0.5 \mathrm{M}$, TRIS pH $7.210 \mathrm{mM}$, EDTA $1 \mathrm{mM}$ ) and $10 \mathrm{mM}$ DTT, treated with RNase A $20 \mu \mathrm{g} / \mathrm{ml}$ (Pharmacia LKB, Piscataway, NJ, USA) in NTE at $37^{\circ} \mathrm{C}$ and washed in NTE and in $0.1 \times S S C / 1 \mathrm{mM}$ DTT, then coated with photographic emulsion (K5 gel emulsion, Ilford, Cheshire, UK) and exposed for one to two weeks at $4^{\circ} \mathrm{C}$. The film was developed and the sections stained with haematoxylin and eosin.

Immunohistochemistry for CD14 and IL8 Serial sections from several of the formalin fixed tissues used for in situ hybridisation (three Crohn's disease, three ulcerative colitis, and three uninflamed from carcinoma resections) were examined simultaneously for expression of the monocyte cell surface marker CD14, which identifies mucosal macrophages recently recruited from the circulation to the intestine, ${ }^{21}$ as well as weakly staining neutrophils $^{22}$ and B lymphocytes. ${ }^{23}$ Sections were dewaxed in xylene, rehydrated, and microwave treated at $600 \mathrm{~W}$ for 10 minutes in $6 \mathrm{M}$ urea to re-expose cross linked antigen. ${ }^{24}$ Endogenous peroxidase activity was quenched by incubating sections with $0.3 \%$ hydrogen peroxide in methanol. Subsequent incubations were performed at room temperature in a moist chamber. Sections were treated with $4.5 \%$ normal horse serum and then incubated overnight with murine monoclonal antibodies directed against monocytes and macrophages (anti-CD68, Dakopatts, Denmark) and against CD14 (CMRF31: binds to CD14 transfectants, blocks lipopolysaccharide binding - Calder et al, manuscript in preparation; generous gift from Dr Derek Hart, Department of Haematology, Christchurch Hospital, Christchurch, New Zealand), and washed three times. No antibody and irrelevant matched isotype antibodies were used as negative controls. The slides were incubated with a 1:200 dilution of sheep antimouse biotinylated antibody (Amersham International, UK) in phosphate buffered saline (PBS), washed three times in PBS, incubated with avidin/biotinylated horseradish peroxidase complex (ABC, Vector Laboratories, CA, USA), and washed with PBS. Slides then were stained with 3,3'-diaminobenzidine $(0.5 \mathrm{mg} / \mathrm{ml}$, Stansens, Australia), imidazole $(10 \mathrm{mM})$, and hydrogen peroxide $(0.3 \%)$ for five minutes, washed in tap water for five minutes, counterstained with Harris' haematoxylin, and mounted using Histoclad (Clay Adams, Parsippany, NJ, USA). Despite repeated attempts to define conditions that allowed immunohistochemistry for CD14 to be performed on the same tissue sections as in situ hybridisation, morphological results suitable for analysis could not be obtained. Thus serial sections were examined to determine apparent coexpression of IL8 mRNA and CD14 by monocytes/macrophages.

For IL8 immunohistochemistry, colonic tissue from four Crohn's disease, two ulcerative colitis, and four colon carcinoma resections was fixed immediately in $2 \%$ periodate-lysine paraformaldehyde (PLP) ${ }^{25}$ for four hours before overnight washing in $7 \%$ sucrose phosphate buffer. Fixed tissue was embedded in OCT compound (Tissue-Tek, Miles Inc, IN, USA) and stored at $-20^{\circ} \mathrm{C}$. Sections of $5 \mu \mathrm{m}$ were cut, dried, washed to remove OCT, and examined for expression of IL8 protein by immunohistochemistry using the above method, a polyclonal rabbit antibody against IL8 (generous gift from Dr Steven Kunkel, University of Michigan Medical School, Ann Arbor, $\mathrm{MN})^{14}$ and biotinylated sheep-antirabbit IgG (Serotec, Oxford, UK) at a dilution of 1:400 in PBS. Negative controls used included no primary antibody, 
pre-immune rabbit serum, irrelevant rabbit polyclonal antiserum, and anti-IL8 preadsorbed with recombinant human IL8, as described. ${ }^{14}$ Subsequently IL8 staining was performed on formalin fixed tissue (six Crohn's disease, five ulcerative colitis, and seven colon cancer resections, as for in situ hybridisation) treated with $6 \mathrm{M}$ urea as described above.

\section{Intestinal mucosal disaggregation and} macrophage and $T$ cell enrichment

Intestinal mucosa was disaggregated enzymatically as previously described. ${ }^{26}$ Briefly, mucosa was stripped from submucosa within 30 minutes of resection, and washed several times in calcium-magnesium free Hanks's buffered salt solution with $0.75 \mathrm{mM}$ EDTA, then without EDTA. The tissue was minced finely, and incubated overnight in RPMI 1640 (Flow Labs, Australia) with $10 \%$ fetal calf serum, $2 \mathrm{U} / \mathrm{ml}$ collagenase (CLSPA type, Worthington Biochemical Corp, Freehold, NJ, USA), and $5 \mathrm{U} / \mathrm{ml}$ DNase II (Calbiochem, San Diego, CA, USA). The digest was filtered, then centrifuged through Ficoll-Paque (Pharmacia Fine Chemicals AB, Uppsala, Sweden). The resultant mononuclear cell preparation was $>85 \%$ viable by $0 \cdot 1 \%$ trypan blue exclusion.

Macrophages were enriched by fibronectin or $\gamma$ globulin adherence as described previously. ${ }^{27}$ The resulting adherent cells were $75-80 \%$ macrophages as determined by staining with the anti-monocyte/macrophage marker anti-CD68 with viability $>80 \%$. Virtually all contaminating cells were $T$ lymphocytes that stained with anti-CD3 (OKT3, Ortho-mune, NJ, USA).

Intestinal $\mathrm{T}$ cells were enriched from the mononuclear cell population by 2 -aminoethylisothiouronium bromide (AET) sheep red blood cell rosetting as previously described. ${ }^{27}$ The resulting population of $>85 \% \mathrm{~T}$ cells, as determined by staining with anti-CD3, showed viability values $>90 \%$.

All materials used were free of contamination by lipopolysaccharide as determined by limulus amoebocyte assay.

\section{$R N A$ extraction and northern blotting}

Total cellular RNA from macrophages and $T$ cells were extracted by the method of Chomczynski, ${ }^{28}$ quantified by determining optical density at $260 \mathrm{~nm}$, and stored at $-70^{\circ} \mathrm{C}$. RNA (5 $\mu \mathrm{g}$ per lane) was electrophoresed in $1 \%$ agarose-formaldehyde gels and blotted onto nitrocellulose filters. The cDNA for IL8 was labelled with $\alpha^{32} \mathrm{P}-\mathrm{dCTP}$ by random priming and used to probe northern blots. A similarly labelled CDNA for $18 \mathrm{~S}$ ribosomal (r)RNA was used as a control to determine equal loading of lanes. Non- specific radioactivity was removed by washing the blots in $2 \times \mathrm{SSC}(0.3 \mathrm{M} \mathrm{NaCl}, 30 \mathrm{mM}$ trisodium citrate) and $0 \cdot 1 \%$ sodium dodecyl sulphate at $60^{\circ} \mathrm{C}$. Labelled blots were exposed to radiography film (XAR5, Eastman Kodak,
Rochester, NY, USA) at $-70^{\circ} \mathrm{C}$ for one to four days then developed.

IL8 secretion by isolated intestinal macrophages Isolated macrophages from four IBD resections (two ulcerative colitis and two Crohn's disease) and from five uninflamed colon cancer resections were enriched by adherence to human $\gamma$ globulin. Adherent macrophages at $1 \times 10^{6} / \mathrm{ml}$ were stimulated for six hours by sonicated lipopolysaccharide ( $\operatorname{Re} 595$ from Salmonella minnesota) at concentrations of 0,1 , 10 , and $100 \mathrm{ng} / \mathrm{ml}$ in $1 \mathrm{ml}$ RPMI $1640+10 \%$ fetal calf serum. Conditioned media were harvested after six hours and stored at $-70^{\circ} \mathrm{C}$ for subsequent IL8 measurement. IL8 enzyme linked immunosorbent assays (ELISAs) were performed in triplicate according to the manufacturer's instructions (Quantikine, $R \& D$ Systems, Minneapolis, MN, USA).

\section{Lipopolysaccharide stimulated peripheral blood monocytes}

Peripheral blood was collected from three healthy volunteer blood donors and buffy coats subjected to density gradient centrifugation with Ficoll-Paque to obtain mononuclear cells, and monocytes enriched by adherence to human $\gamma$ globulin as described above. Monocytes comprised $>85 \%$ of these cells and viability values exceeded $90 \%$. Adherent monocytes were stimulated for six hours by sonicated $\mathrm{Re}$ 595 lipopolysaccharide at a concentration of 10 $\mathrm{ng} / \mathrm{ml}$ after preliminary experiments showed optimum IL8 mRNA expression at this value (data not shown). Cells were treated simultaneously with hydrocortisone $200 \mu \mathrm{g} / \mathrm{ml}$ (Glaxo, Melbourne, Australia) or 5-aminosalicylic acid $500 \mu \mathrm{g} / \mathrm{ml}$ (Pharmacia, Sydney, Australia), or cyclosporin A $100 \mathrm{ng} / \mathrm{ml}$ (Sandoz, Switzerland), or all three, as previously outlined. ${ }^{7}$ Conditioned media were harvested after six hours and stored at $-70^{\circ} \mathrm{C}$ for later IL8 measurement by ELISA and RNA was extracted, electrophoresed, and blotted as described above, probed with IL8 and 18S rRNA CDNA probes then exposed to radiography film at $-70^{\circ} \mathrm{C}$.

\section{Statistics}

Data are expressed as mean (SEM) and statistical analysis performed using analysis of variance with a Fisher's protected least significant difference post hoc test. Nominal data were compared by $\chi^{2}$ analysis. Significance was considered to be present if $\mathrm{p}<0 \cdot 05$.

\section{Ethics}

The acquisition and use of human blood and tissue for this study was approved by the ACT Health Institutional Ethics Committee.

\section{Results}

IL8 in situ hybridisation

IL8 mRNA was not detected in the seven 

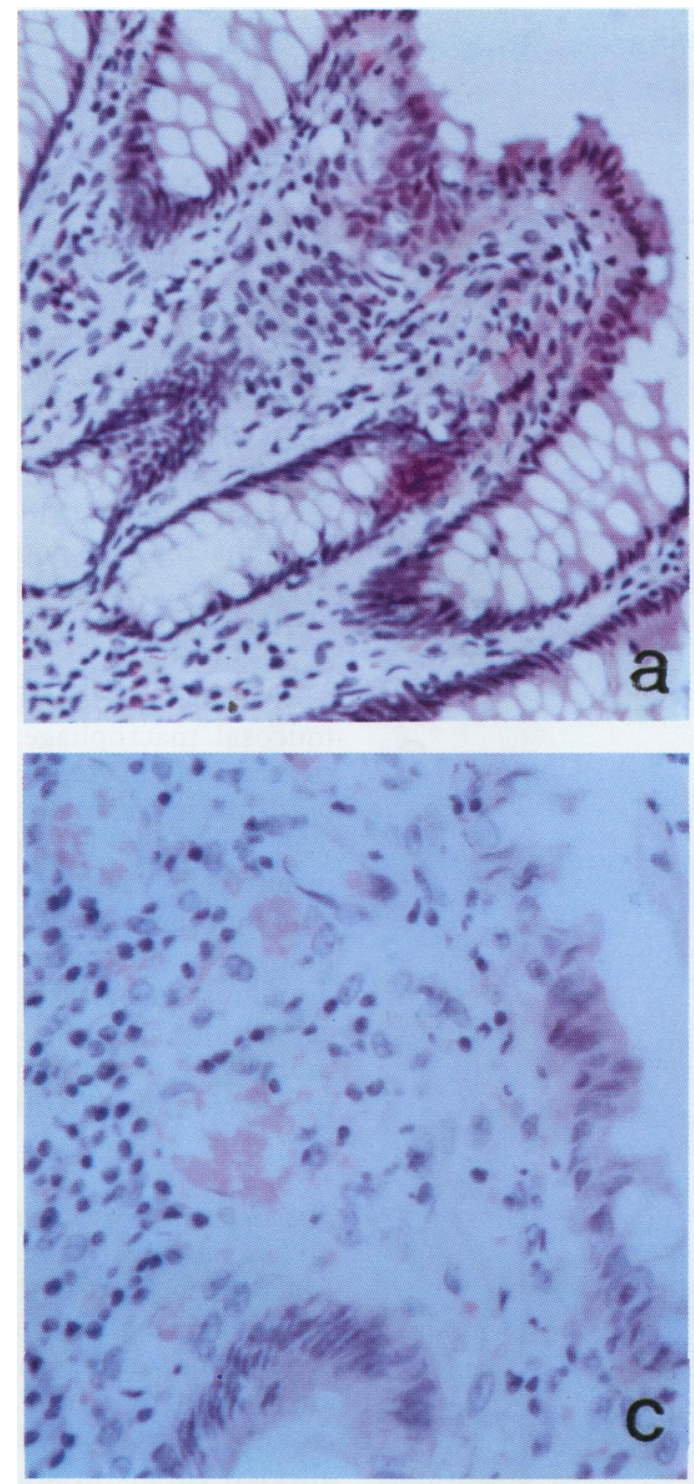

Figure 1: IL8 by situ hybridisation. (a) Normal colon expresses no IL 8 mRNA using the antisense IL 8 probe; (b) ulcerative colitis expresses IL 8 mRNA (autoradiographic grains - arrow) in subepithelial macrophages using the antisense IL 8 probe. Epithelial cells are negative; (c) ulcerative colitis examined with the IL8 sense probe is negative; (d) Crohn's disease also expresses IL 8 mRNA in macrophages in a perivascular distribution (antisense probe); (e) Crohn's disease, showing dilated submucosal vessels, examined with the IL8 sense probe is negative. Magnification - $a, c: 400 \times ; b, d, e: 800 \times$.

normal colon sections examined using the antisense probe (Fig 1a). Examination of the five ulcerative colitis and six Crohn's disease tissues with the antisense probe consistently showed abundant mRNA for IL8 in cells morphologically and phenotypically (CD68 positive data not shown) resembling macrophages in proximity to ulcerated epithelium, as well as in many neutrophils in lamina propria, ulcer slough, and crypt abscesses. IL8 expression was found predominantly in areas below and adjacent to active ulceration, but isolated IL8 expressing cells also were apparent in inflamed mucosa displaying intact epithelium (Fig 1b) and in a perivascular distribution (Fig $1 \mathrm{~d}$ ). In situ hybridisation using the sense probe for IL8 was repeatedly negative in all tissues examined (Fig 1c and e). There was no demonstrable IL8 mRNA in epithelial cells, either adjacent to or away from areas of ulceration in IBD tissues
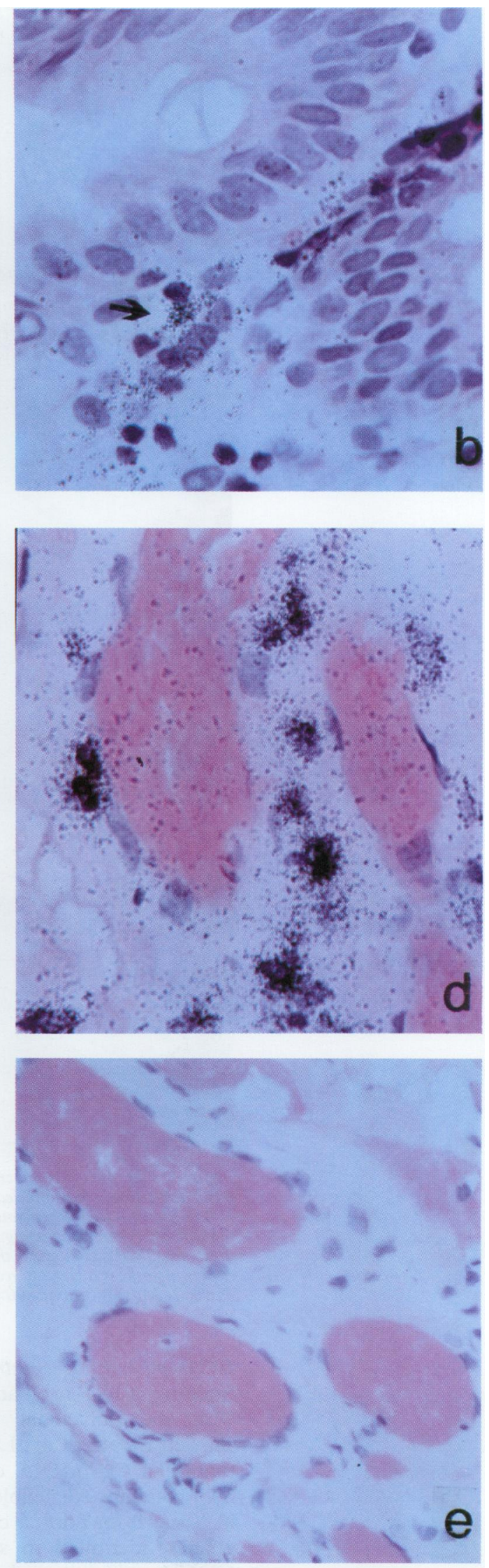

(Fig 1b), nor was IL8 expressed in normal colon epithelial cells (Fig 1a).

In three experiments serial sections stained with the anti-CD14 antibody, CMRF31, showed that many of the IL8 mRNA expressing macrophages also seemed to express the monocyte marker CD14, suggesting their recent arrival from the circulation as previously described $^{21}$ (Fig 2a and b). 


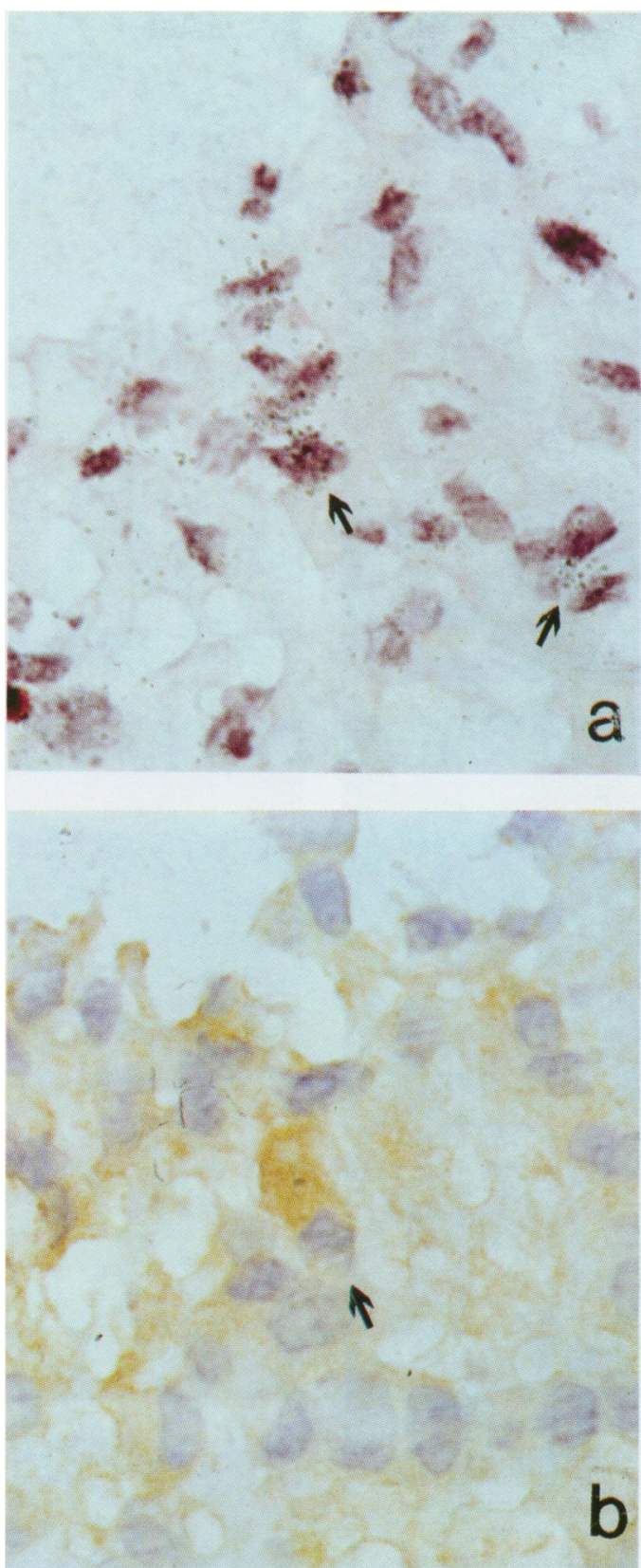

Figure 2: CD14 positive macrophages express IL8 $m R N A$. (a) Subulceration mononuclear cells express $m R N A$ for IL8 in ulcerative colitis (arrows); (b) serial section stained immunohistochemically using the anti-CD14 monoclonal antibody CMRF31 suggests that at least one of the IL8 expressing cells is a recently recruited monocyte/macrophage (arrow). Magnification: $800 \times$.

\section{IL8 immunohistochemistry}

Staining of PLP fixed and formalin fixed tissues with the polyclonal antibody against IL8 showed a pattern of IL8 production similar to that seen for mRNA expression with in situ hybridisation. Negligible IL8 staining was seen in tissue from normal colons (Fig 3a). Macrophages, identified in serial sections by their CD68 positivity, and neutrophils associated with ulceration in all seven ulcerative colitis and 11 Crohn's disease specimens were strongly positive for IL8, as were neutrophils in crypt abscesses (Fig 3c and e). Little IL 8 staining was seen away from active epithelial ulceration. Tissue incubated using anti-IL8 pre-adsorbed with recombinant human IL8 was negative in all sections examined (Fig $3 b$, d, and $f$ ). As for in situ hybridisation, immunohistochemistry failed to show IL8 production by colon epithelial cells.

\section{Northern blots of isolated lamina propria} mononuclear cells and peripheral blood monocytes To conform intestinal macrophages as IL8 expressing cells, macrophages were isolated from resected intestine. Macrophages from normal intestine expressed MRNA for IL8 in three of 19 cases, while those isolated from IBD tissue expressed IL8 in 20 of 24 cases $\left(\chi^{2}=19.44, \mathrm{p}<0.0001\right)$ (Fig 4a). To control for contaminating $T$ lymphocytes in the isolated macrophage populations, $T$ cells isolated from both normal and inflamed colon also were probed but no IL8 mRNA expression was detected (Fig 4a).

When a model of the recently recruited mucosal macrophage, the lipopolysaccharide treated monocyte, was treated with agents used in the treatment of IBD, IL8 expression was changed. Exposure to hydrocortisone resulted in reduced IL8 mRNA values, although the decrease was less noticeable than that seen for cyclosporin A. In addition, 5-aminosalicylic acid reduced IL8 mRNA expression in lipopolysaccharide treated monocytes, both in the absence and in the presence of hydrocortisone (Fig 4b).

\section{IL8 secretion by isolated intestinal macrophages and by peripheral blood monocytes}

Macrophages isolated from uninflamed colon cancer bearing resections produced low concentrations of IL8 protein, which were not augmented by stimulation using lipopolysaccharide (Fig 5). Macrophages from IBD affected colons produced significantly greater quantities of IL8 than those from uninflamed colons $(p<0.005)$, and this secretion was significantly increased by stimulation using lipopolysaccharide $(p=0.01 ;$ Fig 5$)$. There was no difference between ulcerative colitis and Crohn's disease in the quantity of IL8 generated (data not shown).

To ensure that the observed changes of IL8 mRNA expression in lipopolysaccharide stimulated monocytes were reflected in IL8 protein production, peripheral blood monocytes were stimulated for six hours using lipopolysaccharide. Hydrocortisone, 5-aminosalicylic acid, hydrocortisone plus 5-aminosalicylic acid, and cyclosporin A all produced significant decreases in the quantities of IL8 secreted by lipopolysaccharide stimulated cells (Fig 6).

\section{Discussion}

This study confirms and extends earlier studies $^{82930}$ by showing the cell types involved in IL8 protein production as well as mRNA expression in the mucosa of active IBD. Recently there has been increasing evidence for an active role for neutrophils as mediators in inflammatory reactions, including the production of IL $1 \beta$, IL 6, GM-CSF, tumour necrosis factor (TNF) $\alpha$, and IL 1 receptor antagonist, ${ }^{3}$ 
Figure 3: IL8 by

immunohistochemistry.

(b), (d), and ( $f$. Normal, ulcerdtive colitis, and Crohn's disease colon stained with anti-IL8 pre-adsorbed with

recombinant human IL8.

No cells stain positively;

(a) normal colon stained

with anti-IL8 showing no

positive cells in the lamina

propria; (c) ulcerative

colitis colon stained with

anti-IL8, showing

neutrophils in a crypt

abscess with associated IL8.

Epithelial cells appear to

contain no IL8;

(e) Crohn's disease colon

stained with anti-IL8

showing strong positivity in

lamina propria

macrophages (CD68

positive on serial sections).

Epithelial cells again

appear negative.

Magnification: $400 \times$.
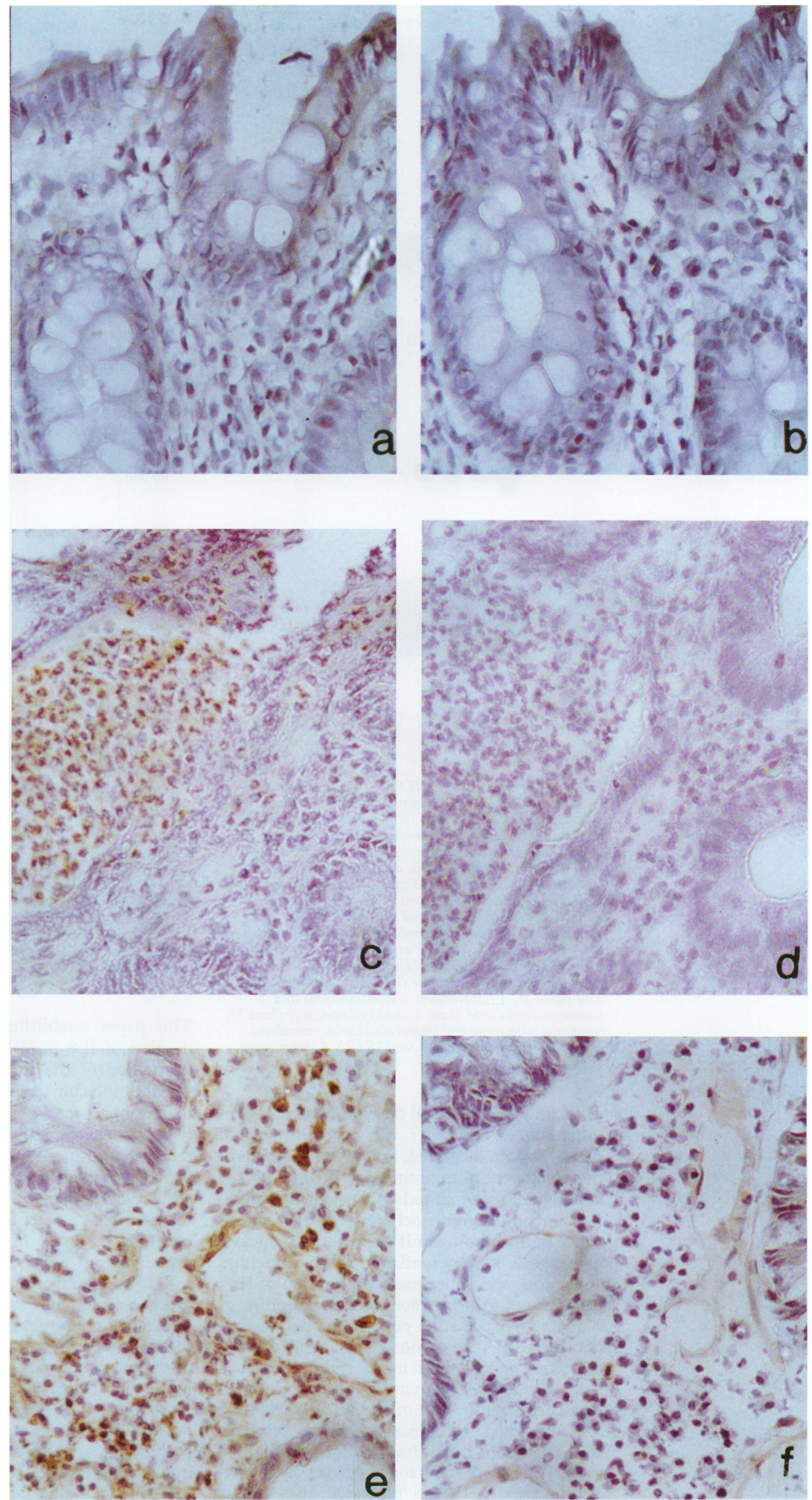


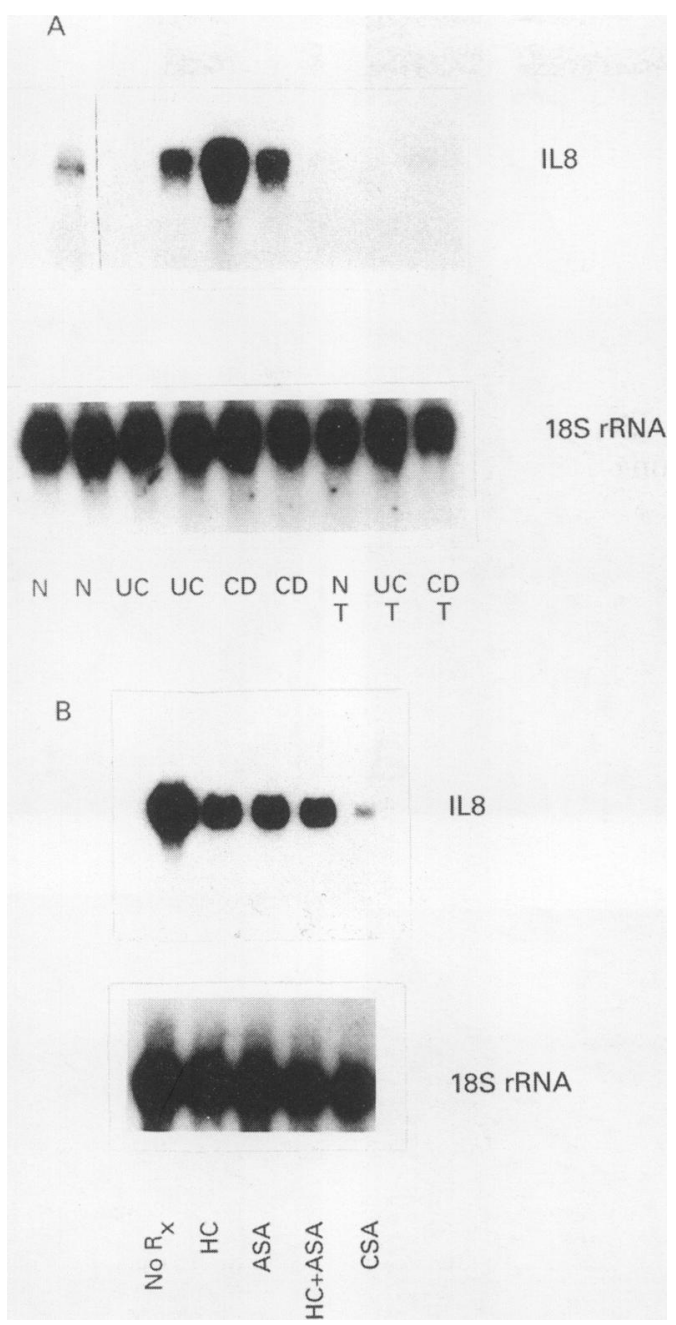

Figure 4: Northern blots for IL8. (a) Representative northern blot for IL8 from isolated intestinal mononuclear cells. Lanes 1 and 2: normal colon macrophages; lanes 3 and 4: ulcerative colitis macrophages; lanes 5 and 6: Crohn's disease macrophages; lanes 7, 8, and 9: T cells from normal, ulcerative colitis, and Crohn's disease respectively. IL8 expression is seen in macrophages from most, but not all IBD resections, while present in few normal colon macrophages and no colonic $T$ cell populations. The same blot probed for $18 S$ rRNA shows equal RNA loading; (b) IL8 expression by

lipopolysaccharide stimulated blood monocytes is reduced by treatment with hydrocortisone (lane 2), 5-aminosalicylic acid (lane 3), a combination of hydrocortisone and 5-aminosalicylic acid (lane 4) and cyclosporin A (lane 5), compared with untreated lipopolysaccharide stimulated monocytes (lane 1). Probing for $18 S$ rRNA shows equal loading of RNA.

in addition to their well described passive, proinflammatory actions. ${ }^{2}$ We have shown that neutrophils in ulcerated, inflamed mucosa produce substantial quantities of IL8, using the complementary methods of in situ hybridisation and immunohistochemistry. The significance of this finding in IBD is that it implicates neutrophils in a potential cycle of attraction, activation, and subsequent production of IL8, permitting further attraction of neutrophils.

In situ hybridisation permits the demonstration of mRNA expression in unchanged tissue and when performed using riboprobes provides exquisite sensitivity. ${ }^{31} \mathrm{~A}$ further advantage is the delineation of all the cells of origin for individual cytokines in tissue sections. Indeed, in situ hybridisation and immunohistochemistry here show macrophages as important sources of IL8 in ulcerated IBD tissue.

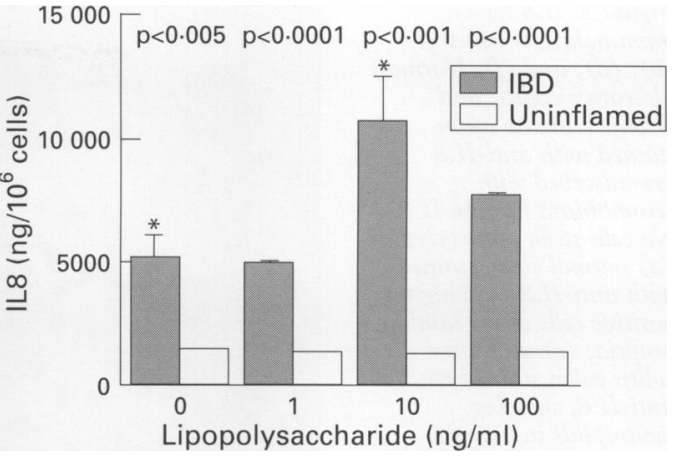

Figure 5: IL8 secretion by lipopolysaccharide stimulated isolated intestinal macrophages. Graph showing IL8 secretion ( $n g / 10^{6}$ cells) on the $y$ axis and lipopolysaccharide dose $(n g / m l)$ on the $x$ axis, showing low level IL8 production by macrophages from uninflamed colon cancer bearing resections, not augmented by lipopolysaccharide stimulation. By contrast, macrophages from IBD affected colons produce significantly more IL8, which is increased significantly by stimulation using lipopolysaccharide. ${ }^{\star} p=0.01$. Data expressed as mean (SEM).

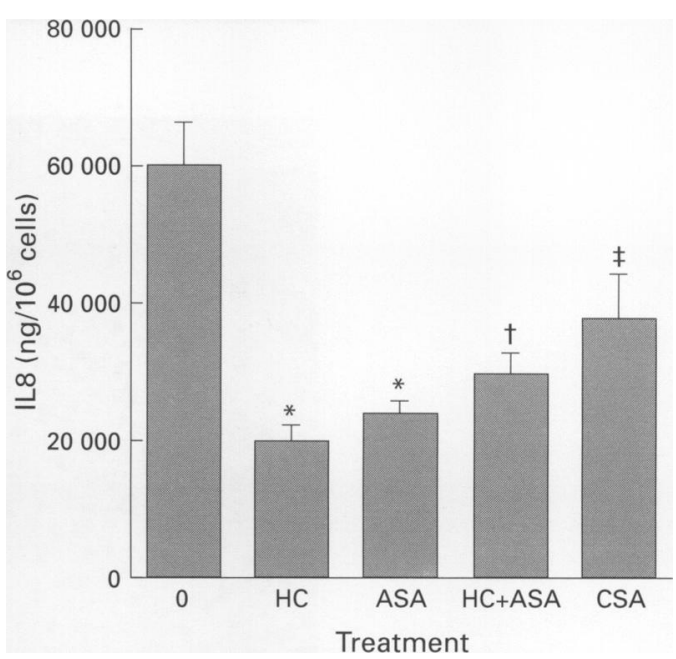

Figure 6: IL8 secretion by lipopolysaccharide stimulated peripheral blood monocytes. Graph showing IL8 secretion ( $n g / 10^{6}$ cells) in lipopolysaccharide stimulated monocytes (0) is inhibited by treatment using hydrocortisone (HC), 5-aminosalicylic acid ( $A S A)$, hydrocortisone plus 5-aminosalicylic acid $(H C+A S A)$ and cyclosporin $A$ $(C S A) .{ }^{\star} p<0.0001 ; \dagger p=0.0003 ; \ddagger p=0.003$. Data expressed as mean (SEM).

This paper establishes that macrophage production of IL8 in IBD is associated with the expression of the marker CD14. CD14 is a surface molecule usually absent from intestinal macrophages but present on increased numbers of cells in $\mathrm{IBD}^{32}$ and a marker of the recent recruitment of monocytes from the circulation, ${ }^{21}$ in addition to being present on the surface of neutrophils ${ }^{22}$ and B lymphocytes. ${ }^{23}$ CD14 acts as a receptor for lipopolysaccharide bound to its carrier lipopolysaccharide binding protein and it allows macrophages to be activated by $\mathrm{pg} / \mathrm{ml}$ concentrations of lipopolysaccharide. ${ }^{33}$ Its absence from normal intestinal macrophages probably results in their reduced responsiveness to low concentrations of lipopolysaccharide. ${ }^{34}$ More importantly, however, its presence on intestinal macrophages expressing IL8 shows that recently arrived monocytes contribute to the continuing attraction of neutrophils to IBD mucosa, and suggests a mechanism by which lipopolysaccharide in the inflamed mucosal 
environment may stimulate neutrophil recruitment.

Significantly, IL8 expression is confined largely to areas of ulceration or those closely adjacent; inflamed mucosa displaying intact epithelium shows little IL8 production. This finding may relate to the quantity of lipopolysaccharide and other bacterial products that have ready access to lamina propria cells in regions where the epithelial barrier is disrupted, resulting in the stimulation of proinflammatory and chemotactic cytokine production thereby attracting further inflammatory cells into the mucosal lesion. The subsequent destructive effects of newly arrived neutrophils may extend the ulceration increasing exposure of the lamina propria to lipopolysaccharide in a positive feedback loop.

We show also that the isolated intestinal macrophage mirrors the in vivo expression of IL8 in IBD. Compared with those from normal colon, significantly greater numbers of IBD mucosal macrophage preparations express IL8 mRNA. Similarly, macrophages isolated from IBD affected mucosa produce greater quantities of IL8 protein than macrophages from uninflamed colon cancer bearing mucosa and while the latter cells seem not to produce more IL8 after stimulation using lipopolysaccharide, IBD macrophages respond to lipopolysaccharide by a significant increase in IL8 secretion. This is an important finding and provides a functional correlate for our finding that IBD macrophages, but not macrophages in normal colon, strongly express CD14. ${ }^{32}$

Although it has been shown previously that corticosteroids $^{35}$ and cyclosporin $\mathrm{A}^{36}$ may inhibit IL8 production we have shown also that 5-aminosalicylic acid down regulates the expression and production of IL8 in a model of the recently recruited intestinal macrophage, the lipopolysaccharide stimulated, CD14 positive blood monocyte. These data provide a further insight into the mechanisms of action of the agents used in the treatment of IBD, and suggests that they work, at least in part, by reducing the attraction of a fresh population of neutrophils to inflamed mucosa.

An important finding from this study is the absence of detectable IL8 production by epithelial cells in both normal and inflamed colon. Epithelial cell IL8 production has been suggested by the finding that some, although not all, lipopolysaccharide stimulated colon cancer cell lines produce appreciable quantities of IL8. ${ }^{16-183738}$ One of these studies ${ }^{18}$ has suggested also that epithelial cell crypts isolated from normal colons produce IL8, but the crypt cell population may have been contaminated by subepithelial macrophages, as the marker used to exclude macrophage contamination was CD14, which is not seen on normal colonic macrophages. ${ }^{32}$ Indeed we also have been able to show IL8 production by isolated colonic crypts, but immunohistochemical analysis of these crypt preparations shows significant contamination by nonepithelial cells, especially macrophages (unpublished findings). Moreover the finding of IL8 secretion by isolated crypt epithelial cells may be an artefact. A recent preliminary report suggests that the process of isolating crypt epithelial cells from human intestine strongly induces IL8 transcription during the first hours of culture in vitro. ${ }^{39}$ Ignoring these caveats and given the sensitivity of riboprobe generated in situ hybridisation, ${ }^{31}$ if epithelial cells do produce IL8 in IBD mucosa it is probably in quantities insufficient to add significantly to the amount expressed by macrophages and neutrophils.

This study has shown a link between the analysis of cell populations isolated from resected colons and the determination of cytokine profiles in the tissue using in situ hybridisation and immunohistochemistry. Work now in progress is aimed at elucidating some of the signals responsible for the attraction of other inflammatory cells to IBD affected mucosa; combined with this study it offers the potential for future treatment directed at blocking the recruitment of leucocytes in IBD.

Dr Michael C Grimm was supported by a National Health and Medical Research Council Postgraduate Medical Scholarship.

The authors would like to thank Ms Erika van de Pol for isolating intestinal T cells, Ms June Hornby for performing isolating intestinal T cells, Ms June Hornby for performing
ELISAs, and the surgeons of Woden Valley Hospital, Garran, ELISAs, and the surgeons of Woden Valley Hospital, Garran,
ACT and Concord Hospital, Concord, NSW for providing ACT and Concord Hospital,
resected intestinal specimens.

1 Podolsky DK. Inflammatory bowel disease (first of two parts). N Engl f Med 1991; 325: 928-37.

2 Weiss SJ. Tissue destruction by neutrophils. $N$ Engl f Med 1989; 320: 365-76.

3 Lloyd AR, Oppenheim JJ. Poly's lament: the neglected role of the polymorphonuclear neutrophil in the afferent limb of
the immune response. Immunol Today 1992; 13: 169-72.

4 Pullman WE, Sullivan PJ, Barratt PJ, Lising J, Booth JA, Doe WF. Assessment of inflammatory bowel disease activity by technetium $99 \mathrm{~m}$ phagocyte scanning. Gastroenterology 1988; 95: 989-96.

5 Lewis RA, Austen KF, Soberman RJ. Leukotrienes and other products of the 5-lipoxygenase pathway. Biochemistry and relation to pathobiology in human diseases. N Engl f Med 1990; 323: 645-55.

6 Sobhani I, Hochlaf S, Denizot Y, Vissuzaine C, Rene E, Benveniste J, et al. Raised concentrations of platelet activating factor in colonic mucosa of Crohn's disease patients. Gut 1992; 33: 1220-5.

7 Pullman WE, Elsbury S, Kobayashi M, Hapel AJ, Doe WF. Enhanced mucosal cytokine production in inflammatory bowel disease. Gastroenterology 1992; 102: 529-37.

8 Raab Y, Gerdin B, Ahlstedt S, Hallgren R. Neutrophil mucosal involvement is accompanied by enhanced local production of interleukin-8 in ulcerative colitis. Gut 1993 34: 1203-6.

9 Jones SC, Evans SW, Lobo AJ, Ceska M, Axon ATR, Whicher JT. Serum interleukin-8 in inflammatory bowel disease. F Gastroenterol Hepatol 1993; 8: 508-12.

10 Oppenheim J, Zachariae COC, Mukaida N, Matsushima $\mathrm{K}$. Properties of the novel proinflammatory supergene 'intercrine' cytokine family. Annu Rev Immunol 1991; 9: 617-48.

11 Taub DD, Oppenheim JJ. Chemokines, inflammation and the immune system. Therapeutic Immunology 1994; 1: 229-46.

12 Anttila HS, Reitamo S, Erkko P, Ceska M, Moser B, Baggiolini $M$. Interleukin-8 immunoreactivity in the skin of healthy subjects and patients with palmoplantar pustulosis and psoriasis. $\mathcal{f}$ Invest Dermatol 1992; 98: 96-101.

13 Seitz M, Dewald B, Gerber N, Baggiolini $M$ Enhanced production of neutrophil-activating peptide-1/ interleukin-8 in rheumatoid arthritis. $\mathcal{F}$ Clin Invest 1991; 87: 463-9.

14 Koch AE, Kunkel SL, Pearce WH, Shah MR, Parikh D, Evanoff HL, et al. Enhanced production of the chemotactic cytokines interleukin-8 and monocyte chemoatrotactic cytokines int Erleukin-8 and monocyte chemoattractant protein-1 in human abdomin

15 Van Zee KJ, DeForge LE, Fischer E, Marano MA, Kenney JS, Remick DG, et al. IL-8 in septic shock, endotoxemia, and after IL-1 administration. 7 Immunol 1991; 146: $3478-82$.

16 Schuerer-Maly C-C, Eckmann L, Kagnoff MF, Falco MT, Maly F-E. Colonic epithelial cell lines as a source of interleukin-8: stimulation by inflammatory cytokines and bacterial lipopolysaccharide. Immunology 1994; 81: 85-91. 
17 Hornby J, Olsen J, Doe WF. Interleukin-8 secretion by colon epithelial cells. F Gastroenterol Hepatol 1993; 8: A11.

18 Eckmann L, Jung HC, Schürer-Maly C, Panja A Morzycka-Wroblewska E, Kangoff MF. Differential cytokine expression by human intestinal epithelial cell cytokine expression by human intestinal epithelial cell
lines: regulated expression of interleukin-8. Gastroenterology 1993; 105: 1689-97.

19 Cox KH, DeLeon DV, Angerer LM, Angerer RC. Detection of mRNAs in sea urchin embryos by in situ hybridization using asymmetric RNA probes. Dev Bio 1984; 101: 485-502.

20 Pyke C, Kristensen P, Ralfkiær E, Grøndahl-Hansen I Eriksen J, Blasi F, et al. Urokinase-type plasminogen activator is expressed in stromal cells and its receptor in cancer cells at invasive foci in human colon adenocarcinomas. Am f Pathol 1991; 138: 1059-67.

21 Grimm MC, Pullman WE, Bennett GM, Sullivan PJ, Pavl P, Doe WF. Direct evidence of monocyte recruitment to $P$, Doe WF. Direct evidence of monocyte recruitment to
inflammatory bowel disease mucosa. $f$ Gastroenterol Hepatol 1995; 10: 387-95.

22 Haziot A, Tsuberi BZ, Goyert SM. Neutrophil CD14 - biochemical properties and role in the secretion of tumour necrosis factor- $\alpha$ in response to lipopolysaccharide. f Immunol 1993; 150: 5556-65.

23 Ziegler-Heitbrock HWL, Pechumer H, Petersmann I Durieux JJ, Vita N, Labeta MO, et al. CD14 is expressed and functional in human B cells. Eur F Immunol 1994; 24: $1937-40$.

24 Cattoretti G, Pileri S, Parravicini C, Becker MHG, Poggi S, Bifulco $\mathrm{C}$, et al. Antigen unmasking on formalin-fixed, paraffin-embedded tissue sections. I Pathol 1993; 171 83-98.

25 McLean IW, Nakane PK. Periodate-lysine-paraformaldehyde fixative - a new fixative for immunoelectro microscopy. I Histochem Cytochem 1974; 22: 1077-83. 26 Golder JP, Doe WF. Isolation and preliminary characterization of human intestinal macrophages. Gastroenterology 1983; 84: 795-802.

27 Pavli P, Hume DA, Van de Pol E, Doe WF. Dendritic cells, the major antigen-presenting cells of the human colonic lamina propria. Immunology 1993; 78: 132-41.

28 Chomczynski P, Sacchi N. Single-step method of RNA isolation by acid guanidinium thiocyanate-phenol-chloroform extraction. Anal Biochem 1987; 162: 156-9.
29 Isaacs KL, Sartor RB, Haskill S. Cytokine messenger RNA profiles in inflammatory bowel disease mucosa detected by polymerase chain reaction amplification. by polymerase chain reaction

30 Mazzucchelli L, Hauser C, Zgraggen K, Wagner H, Hess $\mathrm{M}$, Laissue JA, et al. Expression of interleukin-8 gene in inflammatory bowel disease is related to the histologica grade of active inflammation. Am $\mathcal{F}$ Pathol 1994; 144: 997-1007.

31 Birk PE, Grimm PC. Rapid nonradioactive in situ hybridization for interleukin-2 mRNA with riboprobes generated using the polymerase chain reaction. $\mathcal{f}$ Immunol Methods 1994; 167: 83-9.

32 Grimm MC, Pavli P, van de Pol E, doe WF. Evidence for CD14-positive population of monocytes in inflammatory CD14-positive population of monocytes in inflammatory
bowel disease mucosa - implications for pathogenesis. bowel disease mucosa - implications

33 Wright SD, Ramos RA, Tobias PS, Ulevitch RJ, Mathison JC. CD 14, a receptor for complexes of lipopolysaccharide (LPS) and LPS binding protein. Science 1990; 249: 1431-3.

34 Stephens RW, Golder JP, Fayle DRH, Hume DA, Hapel AJ, Allan W, et al. Minactivin expression in human monocyte and macrophage populations. Blood 1985; 66: 333-7.

35 Cunha FQ, Ferreira SH. The release of a neutrophil chemotactic factor from peritoneal macrophages by endotoxin: inhibition by glucocorticoids. Eur f Pharmacol 1986; 129: 65-76.

36 Zipfel PF, Bialonski A, Skerka C. Induction of members of the IL-8/NAP-1 gene family in human T lymphocytes is suppressed by cyclosporin A. Biochem Biophys Res Commun 1991; 181: 179-83.

37 Eckmann L, Kagnoff MF, Fierer J. Epithelial cells secrete the chemokine interleukin- 8 in response to bacterial entry. Infect Immun 1993; 61: 4569-74.

38 McCormick BA, Colgan SP, Delparcher C, Miller SI, Madara JL. Salmonella-typhimurium attachment to human intestinal epithelial monolayers - transcellular signalling to subepithelial neutrophils. F Cell Biol 1993; 123: 895-907.

39 Gibson PR Rosella O. Interleukin-8 secretion by colonic epithelial cells in vitro: modulation and the effect of disease. Gastroenterology 1994; 106: A687. 